bioRxiv preprint doi: https://doi.org/10.1101/351270; this version posted June 20, 2018. The copyright holder for this preprint (which was not certified by peer review) is the author/funder, who has granted bioRxiv a license to display the preprint in perpetuity. It is made available under aCC-BY 4.0 International license.

\title{
Non-invasive ultrasonic modulation of visual evoked response by GABA delivery through the blood brain barrier
}

\author{
C. Constans ${ }^{1,2,3,4}$, H. Ahnine ${ }^{5}$, M. D. Santin ${ }^{5}$, S. Lehericy ${ }^{5}$, M. Tanter ${ }^{1,2,3}$, P. Pouget ${ }^{5 *}$, J-F Aubry ${ }^{1,2,3 *}$ \\ 1- INSERM U979, Institut Langevin, Paris, France \\ 2- ESPCI Paris, PSL Research University, Institut Langevin, Paris, France \\ 3- CNRS UMR 7587, Institut Langevin, Paris, France \\ 4- Université Paris Diderot, Sorbonne Paris Cité, Paris, France \\ 5- Institut du Cerveau et de la Moelle épinière, ICM, Centre de NeuroImagerie de Recherche, \\ CENIR, Inserm U 1127, CNRS UMR 7225, Sorbonne Université, F-75013, Paris, France
}

\begin{abstract}
We demonstrate the feasibility of non-invasively modulating the visual cortex activity of non-human primates by local ultrasound-induced delivery of an inhibitory neurotransmitter (GABA). GABA was injected intravenously after the blood brain barrier (BBB) was transiently disrupted with focused ultrasound (FUS) coupled with ultrasound contrast agents (UCA). Visual evoked potentials exhibited a significant and progressive decrease of the activity. Combined effects of neuromodulation and BBB opening were shown to be 8.7 times less important than GABA-induced inhibition. During the sonication, the UCA harmonic response was monitored to estimate the level of stable cavitation (signature of BBB opening efficiency) and to avoid damages due to inertial cavitation (automatic shutdown of the sonication when detected). As recent developments in beam forming have shown that ultrasound beams can be focused non-invasively in deep-seated human brain locations, our results hold promise to explore and treat the brain with a non-invasive, controllable, repeatable and reversible method.
\end{abstract}

\section{Introduction}

The blood brain barrier (BBB) naturally prevents large molecules (more than 0.4 to $0.5 \mathrm{kDa}$ ) from diffusing through the capillary walls of the brain ${ }^{1,2}$. While protecting the brain from numerous toxic agents, it also prevents potential medication for brain diseases to being administered through the blood ${ }^{3}$. The BBB can be temporary and reversibly lifted ${ }^{4,5}$ through the intravascular injection of microbulles coupled with low-intensity ultrasound ${ }^{6,7}$ : the acoustic wave induces the bubbles oscillations in the fine brain capillaries, leading to the temporary disruption of the cohesion of endothelial cells through tight junctions which ensured the BBB efficiency. The BBB opening lasts a few hours ${ }^{8}$ and its safety has been investigated in several studies on small animals ${ }^{9-13}$ and non-human primates ${ }^{14,15}$, highlighting the possibility of non-destructive, efficient BBB openings with a mechanical index (MI) below 0.46 in rabbits $^{16}$ and 0.58 in monkeys ${ }^{14}$. None of these early studies have shown functional consequences of BBB opening.

The technique holds promise for therapeutic drug delivery. A clinical trial has been conducted with the objective of delivering chemotherapy on patients with glioblastoma by opening the BBB with an ultrasound device implanted into the skull ${ }^{17}$. The technique could also provide a novel tool for noninvasive and local brain modulation by delivering inhibiting of stimulating drugs. Current neuromodulation techniques have improved dramatically in the last decades but present incompressible drawbacks: deep brain stimulation ${ }^{18,19}$ and localized injection of neuroactive substances are invasive ${ }^{20}$, optogenetic methods cannot be applied to humans, direct current stimulation ${ }^{21}$ and transcranial magnetic stimulation $^{22-24}$ have a low spatial resolution ${ }^{25}$ and are limited to cortical brain areas ${ }^{22,26}$. Focused Ultrasound (FUS) techniques are rising as non-invasive, localized neuromodulation tools that can be potentially applied to humans. Modulation with ultrasound alone has been exhibited in both animals and 
bioRxiv preprint doi: https://doi.org/10.1101/351270; this version posted June 20, 2018. The copyright holder for this preprint (which was not certified by peer review) is the author/funder, who has granted bioRxiv a license to display the preprint in perpetuity. It is made available under aCC-BY 4.0 International license.

humans. The observed effects are interestingly varied: modulation of EEG response ${ }^{27,28}$, excitation of neuronal circuits ${ }^{29,30}$, modulation ${ }^{31}$ or elicitation ${ }^{32}$ of sensory sensations, behavioral changes ${ }^{33,34}$, motor response $^{35-39}$, suppression of the somatosensory evoked potential (SSEP) ${ }^{40}$ and enhancement of neurogenesis ${ }^{41,42}$. However, as the mechanism of FUS-induced neuromodulation is still not fully understood $^{43,44}$ the list of its effects is possibly not complete and as for today, the technique is more in a state of research than a tool for brain mapping or planned modulation. Nevertheless, the advantages of precise ultrasound focusing could be combined with the predictability of neuroactive agents' action with BBB opening. For example $\gamma$-Aminobutyric acid (GABA) is a neuroactive agent which does not normally pass through the $\mathrm{BBB}^{45}$. McDannold et al. $(2015)^{46}$ demonstrated the feasibility to temporary suppress the SSEP in rats by GABA delivery with ultrasonic BBB opening. Zhang et al. $(2016)^{47}$ later disconnected rats brain circuitry by introducing quinolinic acid after magnetic-resonance guided ultrasonic BBB opening. Here we demonstrate that this technique is non-invasive, controllable, repeatable and reversible on anesthetized non-human primates with a real-time monitoring of bubbles harmonic response to ensure both safety and efficiency of the BBB opening. For the first time, functional modulation induced by BBB opening is observed in non-human primates. We targeted the visual cortex of the animals with a single-element transducer operated at $245 \mathrm{kHz}$. We observed a decrease of the visual response intensity to full field visual stimuli and investigated the GABA dose dependency of this effect. The BBB opening was confirmed twice with MRI acquisition. Our goal was to evaluate the relative impact of FUS alone, FUS with UCA, and GABA delivery on the visual response.

\section{Results}

\section{MRI}

To verify the efficiency of the FUS system, we performed two BBB openings on an anesthetized animal before an MRI acquisition. During these experiments, no visual evoked potentials (VEPs) were recorded but the FUS + UCA procedure was identical. We used gadolinium (gadoterate meglumine, DOTAREM ${ }^{\circledR}$, Guerbet, France) as the MR contrast agent (MRCA). Gadolinium has a molecular weight of $938 \mathrm{Da}$ and does not normally pass the $\mathrm{BBB}^{8}$. The diffusion of the MRCA in the brain tissue indicated where the BBB was disrupted.

Both BBB openings proved successful on the images: the MRCA appeared in the occipital and cerebellar areas where ultrasound was focused, after the FUS procedure only. Figure 1 displays the MRI images before and after BBB opening. The signal intensity of turbo spin echo T1-weighted images varied from 1.23 to 2.27 in the targeted region, relatively to a Region of Interest (ROI) defined within neck muscle.
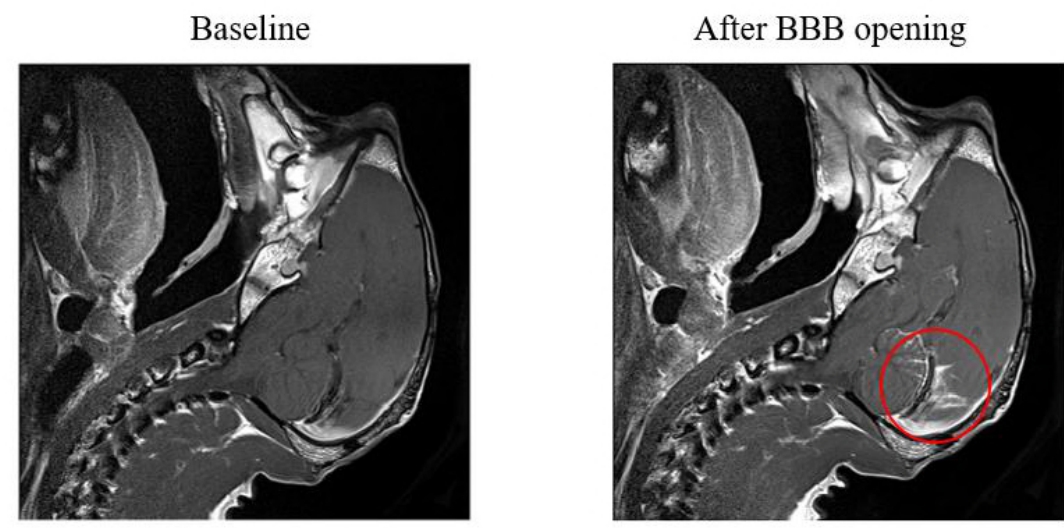

Figure 1: MRI assessment of BBB opening. Both images were obtained 10 minutes after injection of $2 \mathrm{~mL}$ of a $0.5 \mathrm{mmol} / \mathrm{mL} G d$. Left: before BBB opening. Right: after BBB opening. The red circle indicates the region where MRCA appeared. 
bioRxiv preprint doi: https://doi.org/10.1101/351270; this version posted June 20, 2018. The copyright holder for this preprint (which was not certified by peer review) is the author/funder, who has granted bioRxiv a license to display the preprint in perpetuity. It is made available under aCC-BY 4.0 International license.

\section{Response to visual stimuli}

Figure 2 represents the timeline of the procedure. Three ''baseline' runs were performed after installation of the animal and placement of the transducer, prior to any sonication. The animals were installed in sphinx position in front of a black screen. Eyes were kept opened. A run of visual stimuli consisted in 200 full field white flashes with a stimulus onset asynchrony (SOA) of 2s. The animals were placed in a dim room and we waited at least five minutes after the complete extinction of light in the room to start the first run. A 'neuromodulation' sonication was then launched, with the same ultrasound sequence than for BBB opening but without any injection of UCA. The 'neuromodulation' run occurred at the end of this sonication. UCA injection was then performed under the reduced light of a smartphone, via a catheter inserted in the small saphenous vein before light extinction. The ultrasound sequence coupled with the UCA injection was launched, followed by a 'BBB opening, no GABA' run. Finally GABA was injected intravenously $(0.1$ to $6 \mathrm{mg} / \mathrm{kg})$ and at least 3 'GABA' runs were conducted, depending on the animal temperature state.

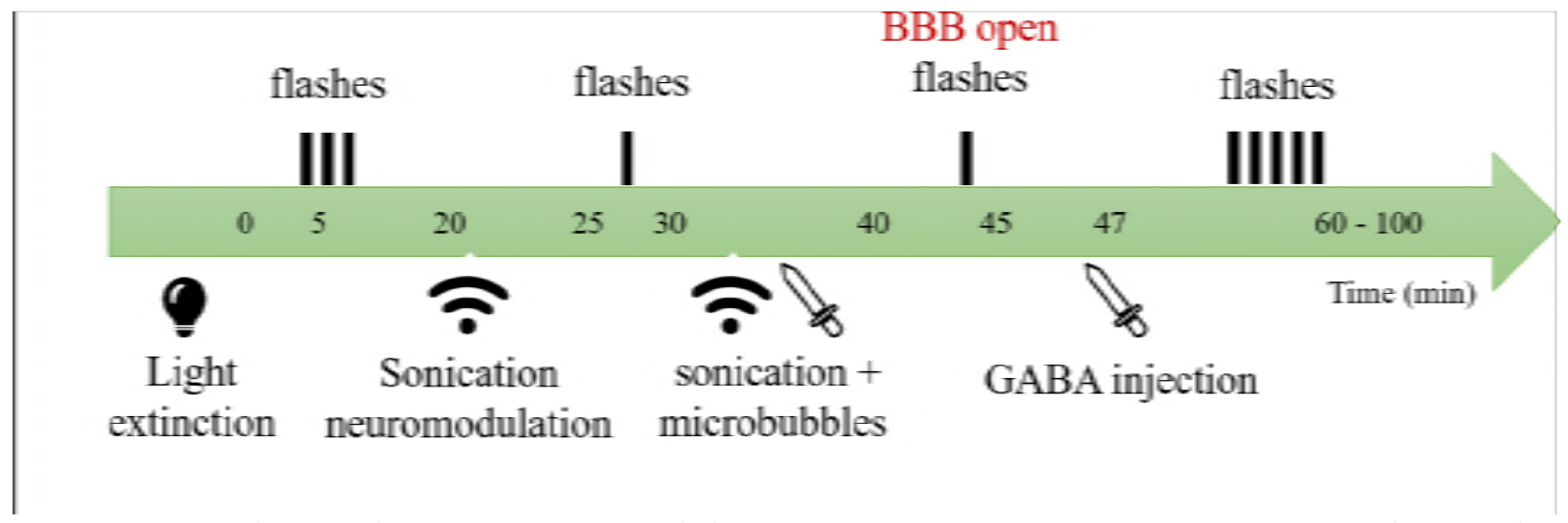

Figure 2: Timeline of the experiments. Each bar represents a VEP run (measurement of the visual responses to 200 full field flashes)

Figure 3 displays the VEP results of one session (monkey A, GABA dose $=5 \mathrm{mg} / \mathrm{kg}$ ). Each curve represents the mean of 200 responses. The 'baseline' curve corresponds to the third baseline run, the first two runs being considered as a period of stabilization and dark adaptation (a total time of 20 minutes). The legend describes the runs in the chronological order. A FUS procedure without UCA is performed between the 'baseline' and 'neuromodulation' runs. Then the BBB is opened with FUS and UCA injection between the 'neuromodulation' and 'No GABA' runs. Finally, GABA is injected intravenously after the 'no GABA' run and the 'GABA' runs are conducted successively, each one lasting about $5 \mathrm{~min}$. Sham sessions were performed without any ultrasound sonication nor UCA and GABA injection, but the timing of VEP recordings was identical to a non-sham session. The runs' names were kept similar to the non-sham sessions ('baseline', 'neuromodulation', 'no GABA', 'GABA'), even though there was no neuromodulation nor GABA injection. 


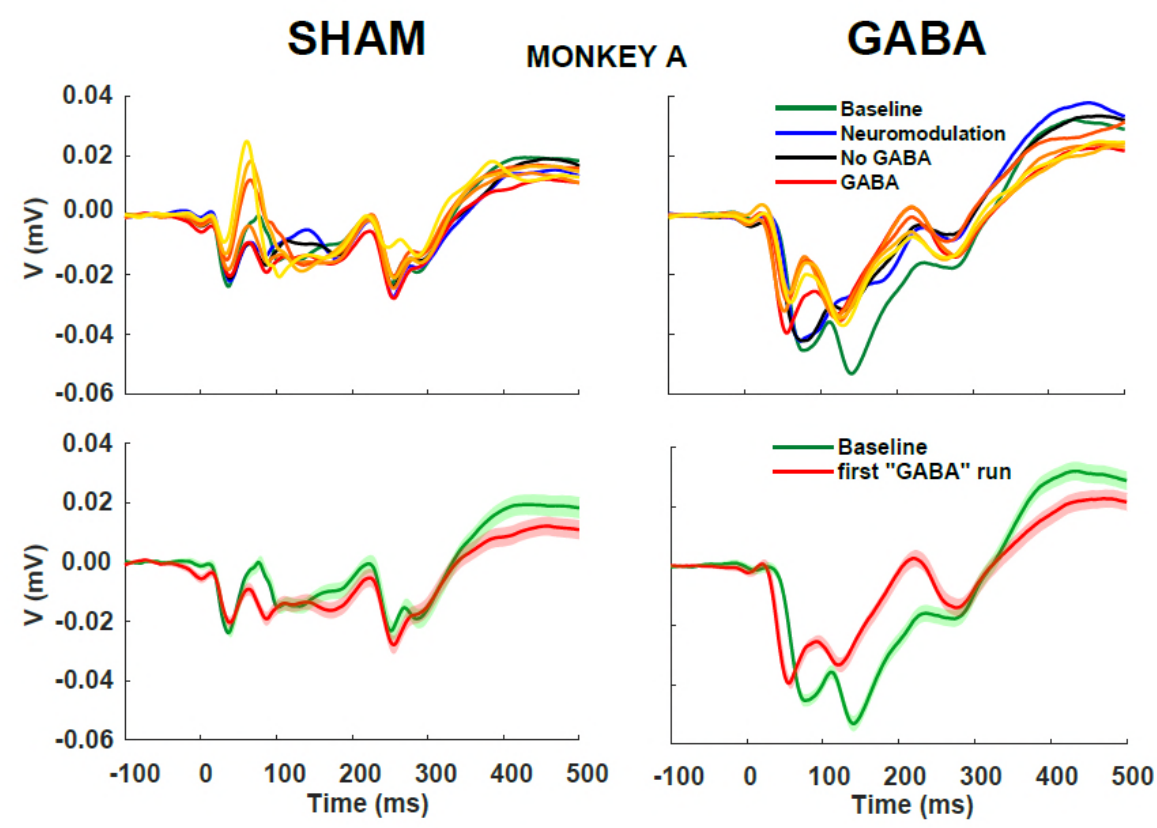

MONKEY B
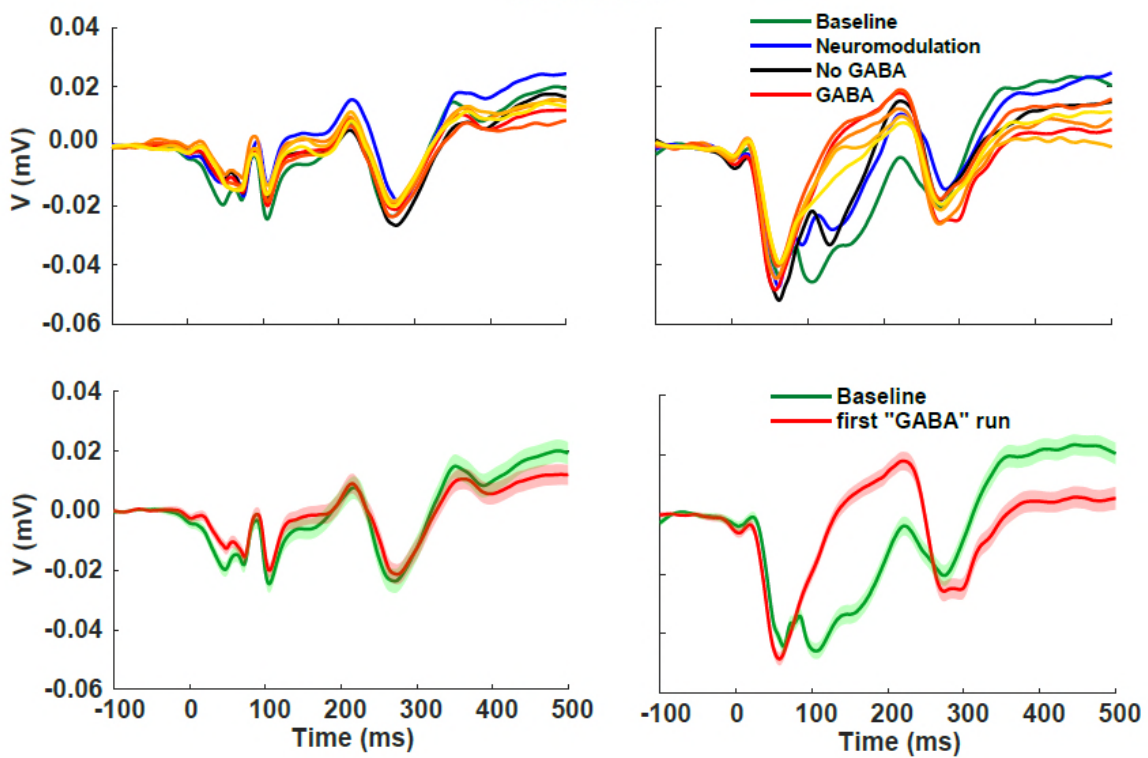

Figure 3: Mean VEP recordings for each run from baseline to 'GABA 5' for sham sessions on both monkeys (left), session $5 \mathrm{mg} / \mathrm{kg}$ GABA dose for monkey A and $4 \mathrm{mg} / \mathrm{kg}$ for monkey B (right). Each curve represents the VEP recordings of one run. The GABA runs are represented in orange gradient colors (red: GABA 1, yellow: GABA 5). The visual stimuli occur at time 0. For clarity purposes, each graph is replicated with only 2 runs (baseline run and first GABA run) with the standard error of the mean (SEM) (rows 2 and 4).

Another illustration of the decrease of visual response for both animals is shown in figure 4. Only two of the recordings under sham conditions and at a $4 \mathrm{mg} / \mathrm{kg}$ GABA dose are displayed for each animal: the average of the VEP recordings of baseline 3 (before BBB opening), and the 'GABA 1' run (after $\mathrm{BBB}$ opening and GABA injection), corresponding to the first 'GABA' run. 

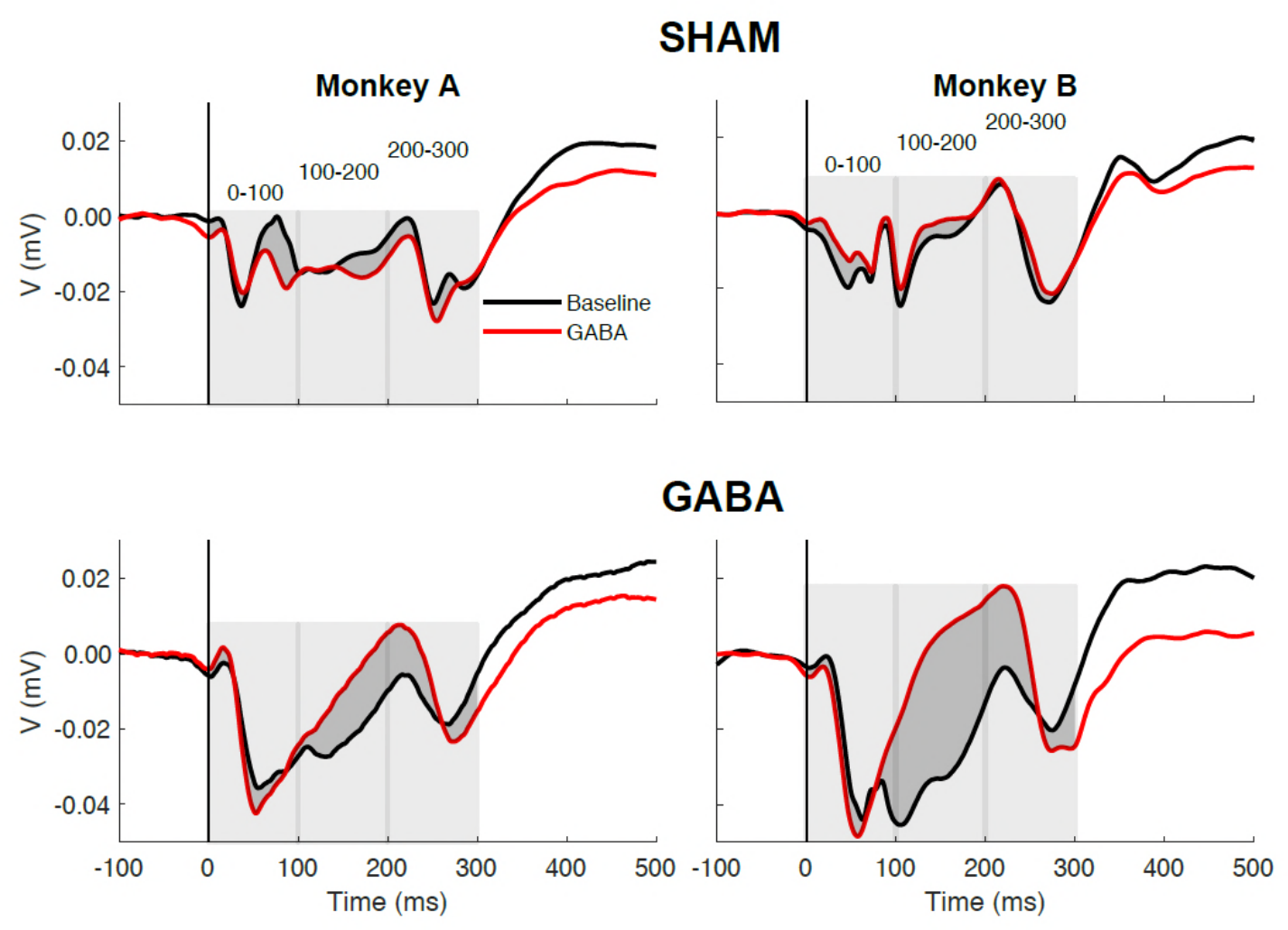

Figure 4: Comparison between the visual response before (Last baseline: black curves) and after ('GABA 1': red curves) neuromodulation by BBB opening and GABA injection for the two animals with a $4 \mathrm{mg} / \mathrm{kg} \mathrm{GABA}$ dose (bottom) or under sham conditions (up). Each curve represents the mean of the 200 VEP recordings.

Finally, we performed a dose study. To quantify the decrease of the visual cortex activity during each session, we considered the decay of the VEPs P1 amplitudes by calculating the difference between the maximum and the minimum P1 peaks over all GABA runs. Figure 5 shows that the impact on P1 amplitude increases linearly when the GABA dose increases. 


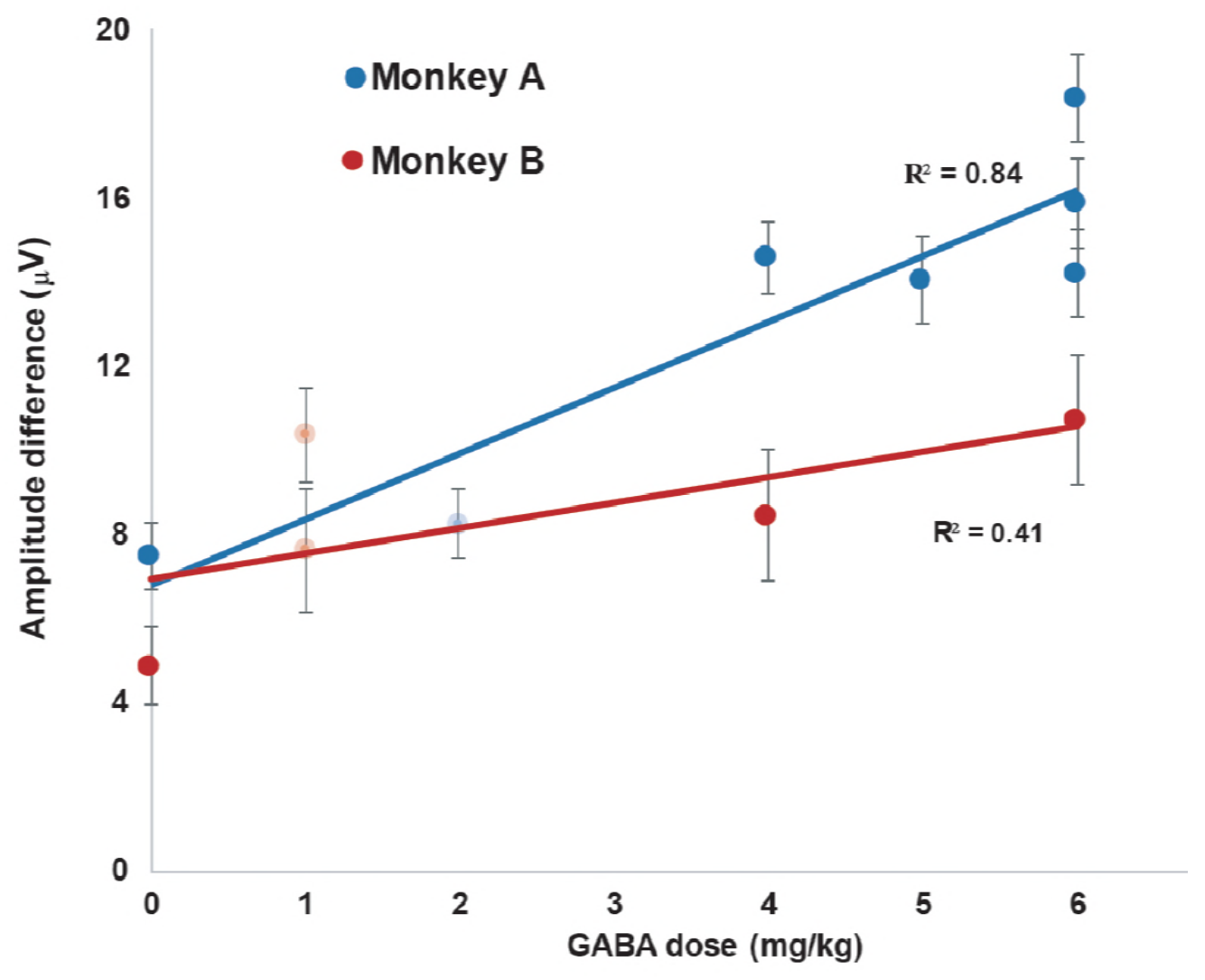

Figure 5. VEPs decrease of amplitude (maximum P1 amplitude - minimum P1 amplitude over the five first GABA runs (except for monkey $A$ - $2 m g$ and monkey $B$ - $1 m g$ with only 3 GABA runs, in light colors)) after GABA injection, as a function of GABA dose.

\section{UCA harmonics content}

For every pulse, the signal received by the hydrophone, monitored on the second channel of the TiePie oscilloscope, was analyzed in the frequency domain. The level of broadband, harmonics, subharmonics and ultraharmonics was displayed in real time. The subharmonic is the signal at half excitation frequency $\mathrm{f}_{0} / 2$ (here, $245 / 2=122.5 \mathrm{kHz}$ ). The subharmonic emission is known to be associated with stable cavitation ${ }^{48,49}$. Harmonics $\left(\mathrm{f}=\mathrm{n} * \mathrm{f}_{0}\right.$ with $\left.\mathrm{n} \geq 2\right)$ and ultraharmonics $\left(\mathrm{f}=(\mathrm{n}+1 / 2) * \mathrm{f}_{0}\right.$ with $\left.\mathrm{n} \geq 1\right)$ emissions, which are also often associated with stable cavitation ${ }^{49}$, were also recorded. The broadband emission corresponds to all the other frequencies. This noise, caused by the collapse of the bubbles, is related to inertial cavitation ${ }^{50,51}$

The bolus injection of $2 \mathrm{~mL}$ of UCA (SonoVue, Bracco, Milan, Italy) took place after the beginning of the sonications, typically between the $20^{\text {th }}$ and $50^{\text {th }}$ seconds (out of 200). A second injection of physiological serum with the same syringe was administrated a few seconds later to flush the rest of UCA that could have deposited in the syringe.

The levels of the different harmonics types and the broadband were first recorded prior to UCA injection. The relative augmentation $\frac{\text { harmonic level }(i) \text {-harmonic level(baseline) }}{\text { harmonic level(baseline) }}$ was calculated for every ultrasonic emission $i$ for all types of harmonics and the broadband. An arbitrary safety threshold of 3 was set for the broadband maximum relative augmentation: if this value was reached, the sonication would be halted automatically. An efficiency threshold was also set to 3 for the harmonics and the subharmonic $\left(\mathrm{f}_{0} / 2\right)$ minimum relative augmentation as an indicator of BBB opening. 
bioRxiv preprint doi: https://doi.org/10.1101/351270; this version posted June 20,2018 . The copyright holder for this preprint (which was not certified by peer review) is the author/funder, who has granted bioRxiv a license to display the preprint in perpetuity. It is made available under aCC-BY 4.0 International license.

Figure 6 displays the relative change of harmonic level for each pulse (one per second) for the session with monkey A at $5 \mathrm{mg} / \mathrm{kg}$, which VEP results were presented previously (figure 2). The bolus injection of UCA started at shot \#15 and ended at shot \#29. The syringe was rinsed with a bolus of physiological serum between shots \#47 and 50 .
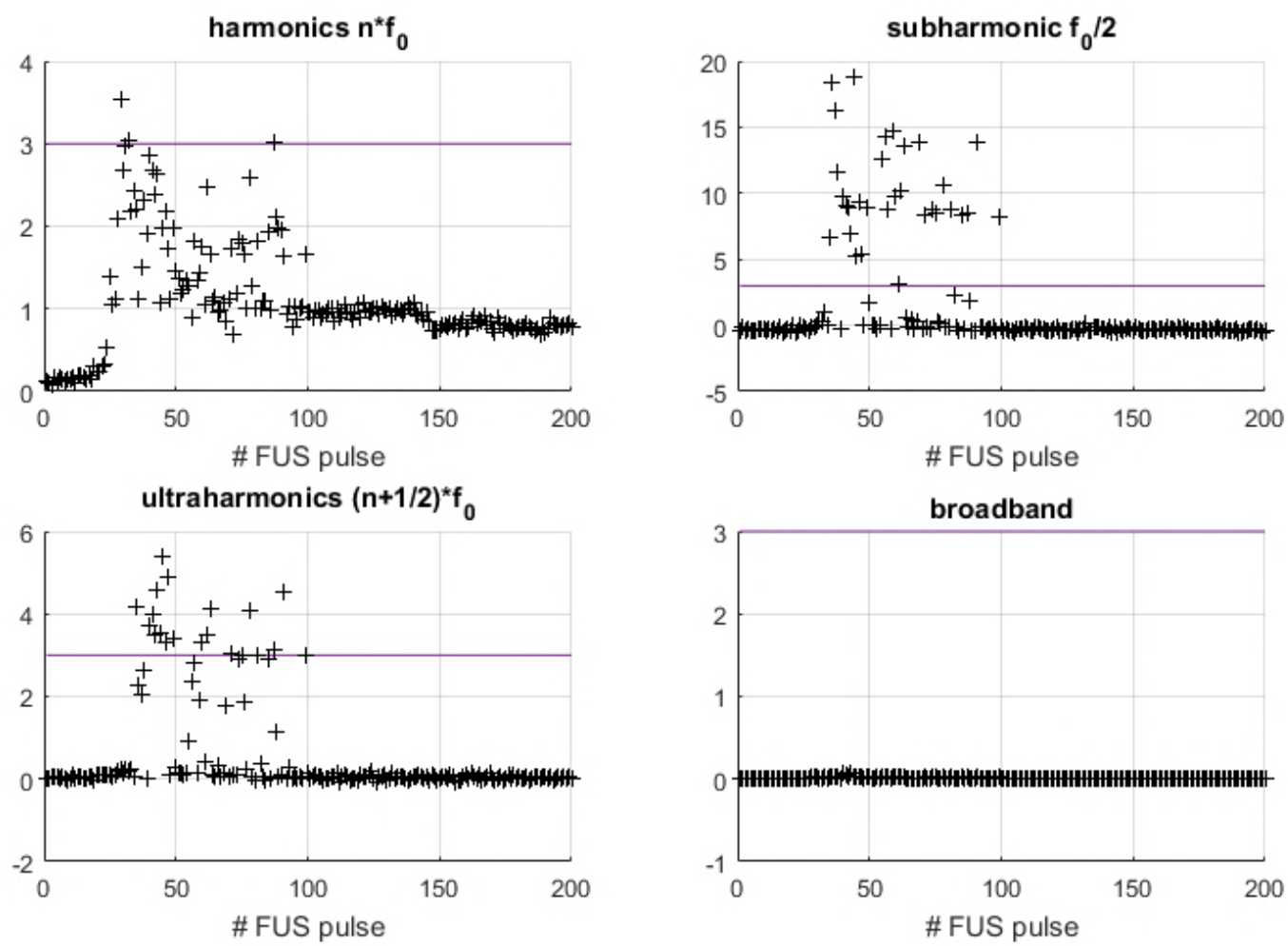

Figure 6: Harmonics and broadband level during BBB opening, session with monkey A at $5 \mathrm{mg} / \mathrm{kg}$.

Figure S1 (supplementary materials) displays the mean harmonic content of the same session before the microbubbles injection (between the $1^{\text {st }}$ and $15^{\text {th }}$ pulses) and after (between the $45^{\text {th }}$ and the $60^{\text {th }}$ pulses). All types of harmonics are clearly emitted during the second period.

The subharmonic emission was above the efficiency threshold for at least 21 seconds for all sessions.

Table 1 (supplementary materials) shows, for each session, the maximum level of relative augmentation for each type of harmonics and broadband. We also calculated the time spent by the subharmonic level above the efficiency threshold.

\section{Discussion}

Analysis of VEPs recordings showed a decrease of the visual response to full field flashes following the GABA dose (figures 3 and 5). The activity was not suppressed entirely, whereas McDannold et al. $(2015)^{46}$ could almost completely inhibit the cortical primary somato-sensory (S1) activity in rats. Several hypotheses could explain this difference.

First, we probably did not reach the GABA dose required to inhibit completely the structures were the BBB was open. Since there is no pharmacology data on BBB disruption-induced GABA in the brain, the dose was limited to $6 \mathrm{mg} / \mathrm{kg}$ in our study for the safety of the animals (due to possible peripheral effect of GABA). For sake of comparison, McDannold et al. $(2015)^{46}$ injected up to $60 \mathrm{mg} / \mathrm{kg}$ in rats. 
bioRxiv preprint doi: https://doi.org/10.1101/351270; this version posted June 20, 2018. The copyright holder for this preprint (which was not certified by peer review) is the author/funder, who has granted bioRxiv a license to display the preprint in perpetuity. It is made available under aCC-BY 4.0 International license.

Second, even at a frequency as low as $245 \mathrm{kHz}$, the focal spot did not cover the entire area involved in the visual circuit, as it can be seen on the MRI (figure 1). In the rat study, BBB disruption was produced in both the cortex and subcortical structures such as the thalamus ${ }^{46}$, hence the possibility of a complete inhibition.

Third, the inhibition of the visual cortex might not be as straightforward as the inhibition of S1 cortex. The contributions of distinct primary visual areas to feedforward and feedback connections to the electrical potential recorded by VEPs are complex to disentangle. Based on peak latencies, an incremental delay between V1, V2, V3, and V3A visual latency has been reported, suggesting serial stages of processing. The extent to which early visual areas have distinct time courses of activation is, however, somewhat contentious ${ }^{52,53}$. According to direct recordings in monkeys, early visual areas first become active nearly simultaneously ${ }^{54,55}$. Additionally, V2, V3, and V3A receive some degree of direct, subcortical input that bypasses $\mathrm{V} 1^{56-61}$.

Historically, single-cell recordings in nonhuman primates have shown that inactivation of higher-order areas modulates neuronal responses in lower-order areas ${ }^{62-65}$. It has been shown that V1 activity is modulated by GABA inhibition of area V2. Another study found similar results for V1, V2, and V3 neurons when area MT was inactivated ${ }^{66}$. Many studies indicate feedback signals mediating surround suppression of V1 neurons. Taken together these results strongly support the role of feedback from higher visual areas in determining V1 neural activity. Feedback interactions in human vision were also reported recently. It has also have been shown that early (40-100 ms) inactivation of V1, using transcranial magnetic stimulation (TMS), inhibits detection of simple features, but not conjunctions ${ }^{56}$. Conversely, inactivation of V1 after longer delays (200-240 ms) seems to impair detection of feature conjunctions, while leaving simple feature detection intact. This double-dissociation implicates V1 in feedback loops with higher visual areas, although it does not specify from where such feedback might originate. Other TMS studies ${ }^{67,68}$ specifically indicated feedback inputs from MT to V1 with latencies $80-125 \mathrm{~ms}$ from the stimulus onset.

Using transcranial ultrasound method, McDannold et al. (2015) ${ }^{46}$ raised the question of possible neuromodulation effects on the somatosensorial cortex activity during BBB opening, independently of the GABA inhibition. Indeed, several studies reported that ultrasound-induced neuromodulation can modulate brain function in primates ${ }^{31,33,34,69}$. In 5 out of 7 case, we observed a significant neuromodulation effects, before the GABA injection, between 100 and 300ms after the stimulus onset (figure 3 is one example). We therefore calculated the spectral power of the signals at each step: the baseline run, after ultrasound alone ('Neuromodulation' run), after ultrasound coupled with UCA before GABA injection ('No GABA' run), and finally after GABA injection ('GABA' run). We calculated the mean contribution of each step in the inhibition (corresponding to the spectral power decrease) over all sessions with a GABA dose of at least $4 \mathrm{mg} / \mathrm{kg}$ for three different time periods: $0-100 \mathrm{~ms}, 100-200 \mathrm{~ms}$ and 200-300ms after the stimulus onset (figure 7). The neuromodulation contribution corresponds to the decrease of activity after the 'neuromodulation' run, i.e. the neuromodulation spectral power minus the baseline spectral power; the UCA contribution is the one after the 'no GABA' run, i.e. the 'No GABA' spectral power minus the neuromodulation spectral power; the GABA contribution is the one from the most perturbed 'GABA' run. In this analysis, we considered the spectral power instead of the amplitude in order to quantify the cerebral activity on different time periods after the stimulus onset. Results showed that FUS+UCA influence got stronger as time increases after the visual stimulus onset, compared to GABA-induced effects. The percentage of GABA-induced inhibition relative to the total inhibition (combined effects of neuromodulation, UCA and GABA) is $90 \%$ during the first $100 \mathrm{~ms}, 42 \%$ during the $100-200 \mathrm{~ms}$ period and $50 \%$ during the $200-300 \mathrm{~ms}$ period.

The translation of this work to the human anatomy requires further developments but will be facilitated by the recent development of multi-element transcranial ultrasound devices ${ }^{70-74}$, as well a low cost approach taking advantage of an acoustic lens to compensate for the aberrations induced by the human skull ${ }^{75}$. 

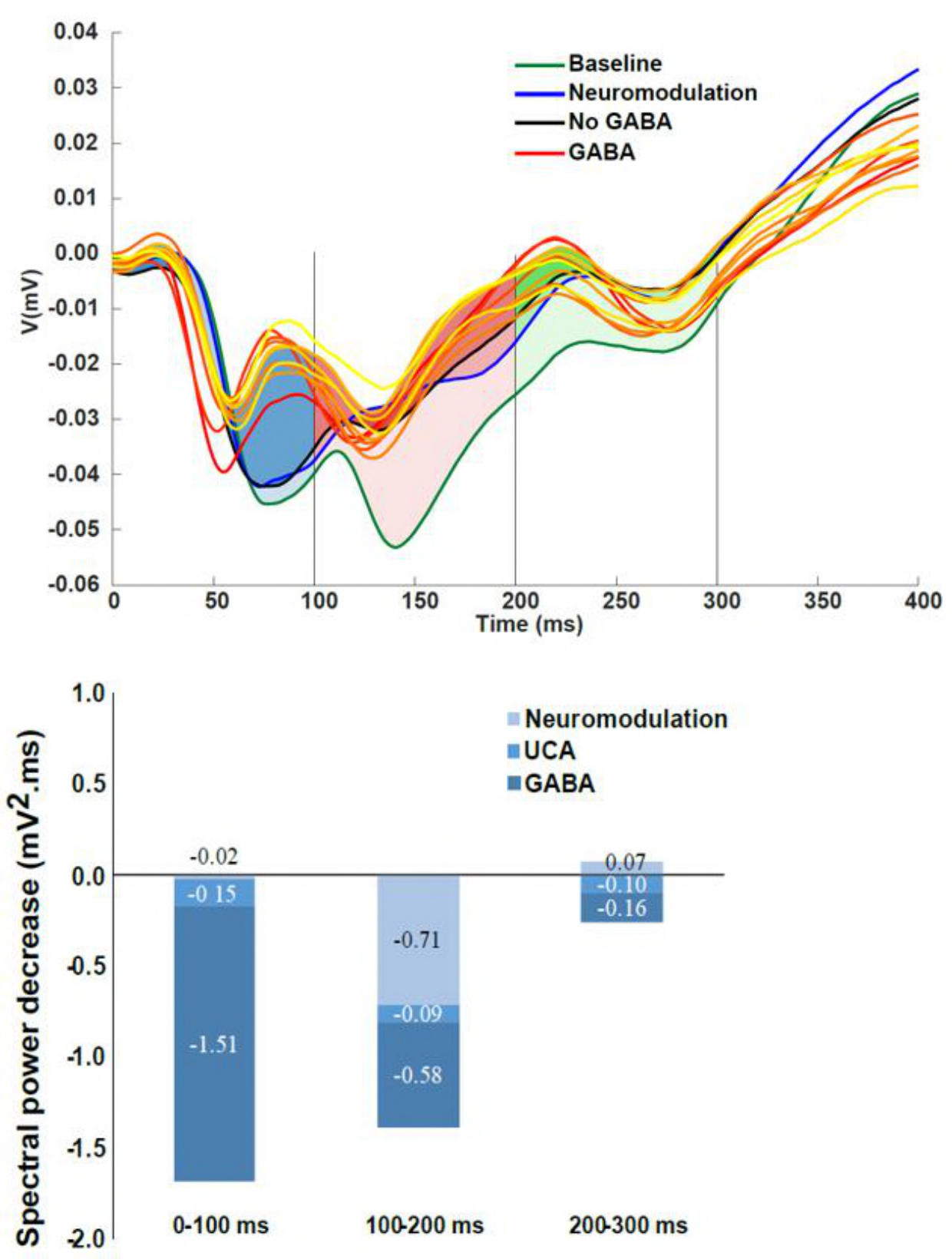

Figure 7. Proportion of the inhibitory effects due to neuromodulation (ultrasound only), BBB opening (ultrasound + UCA) and GABA (after BBB opening and GABA injection). Top: Illustration of the calculation of the contributions from the three events for one session (monkey A, GABA: $5 \mathrm{mg} / \mathrm{kg}$ ). Bottom: Quantification (average of all sessions with a GABA dose of at least $4 \mathrm{mg} / \mathrm{kg}$ on monkey A) of the contributions from neuromodulation, UCA and GABA on VEP spectral power decrease, for three different time periods. 
bioRxiv preprint doi: https://doi.org/10.1101/351270; this version posted June 20, 2018. The copyright holder for this preprint (which was

\section{Materials and methods}

\section{Animals}

Two captive-born macaques (Macaca mulatta 'A' and 'B'), both 6-year-old and respectively 8 and 10 $\mathrm{kg}$, participated to the study. Monkeys were paired-housed and handled in strict accordance with the recommendations of the Weatherall Report about good animal practice. Monkey housing conditions, surgical procedures and experimental protocols were all carried out in strict accordance with the authorization for conducting experiments in our institute delivered by the Animal Health and Veterinary Medication Division of the Department of Public Veterinary Health, Nutrition and Food Safety of the French Ministry of Health (last renewal: Arrêté prefectoral No DTPP B-75-13-19). Monkeys were enrolled in the project 'Thérapie non invasive du cerveau par ultrasons focalisés' (Non-invasive brain therapy using focused ultrasound) validated by the ethical committee C.DARWIN under the reference \#6355. Our routine laboratory procedures included an environmental enrichment program where monkeys had access to toys, mirrors and swings. Monkeys also had visual, auditory and olfactory contacts with other animals and, when appropriate, could touch/groom each other. An institutional veterinary doctor regularly monitored the well-being and health conditions of the monkeys.

Anesthesia was induced with a blend of ketamine hydrochloride ( $3 \mathrm{mg} / \mathrm{kg}$ i.m.) and dexmedetomidine $(0.015 \mathrm{mg} / \mathrm{kg}$ i.m. $)$ for initial sedation and animals were anesthetized with isoflurane during the entire procedure (1.5\% during installation, $1 \%$ during experiments). All procedures lasted less than 3 hours. Heart rate, temperature and respiration were monitored and kept within physiological range. The animal bodies were covered with survival sheets to limit the temperature decrease.

\section{Focused Ultrasound and Harmonics control}

A single element FUS transducer (H117, Sonic Concept, Bothell, WA, USA) (center frequency $261 \mathrm{kHz}$, diameter $64 \mathrm{~mm}$ with $20 \mathrm{~mm}$ central opening, $\mathrm{F}=1$ ) with a passive cavitation detector (PCD) in its center (Y107, Sonic Concept, Bothell, WA, USA, $17.5 \mathrm{~mm}$ active diameter, $64 \mathrm{~mm}$ geometric focus, $10 \mathrm{kHz}$ to $20 \mathrm{MHz}$ bandwidth) was used at the frequency of $245 \mathrm{kHz}$. A coupling cone (C101, Sonic Concepts, Bothell, WA, USA) filled with degassed water was placed between the transducer and the animal head. The transducer was fixed on a mechanical arm with 4 rotation axes (Viewmaster LCD, Osmond Ergonomics, Wimborne, UK) to provide the flexibility for the positioning and orientation of the transducer over the head. The transducer was placed manually, targeting the middle of visual cortex V1, the tip of the cone being place as parallel as possible to the skull surface. A thin layer of echographic gel (Aquasonic 100, Parker Laboratories Inc., Fairfield, NJ, USA) was applied on the shaved skin and on the membrane of the coupling cone to ensure acoustic coupling.

The signal (20ms pulse every second for 200 seconds) was created by a function generator (33250A, Agilent, Santa Clara, CA). A 75-Watts amplifier (75A250A, Amplifier Research, Souderton, PA) was then used to deliver the required power to the transducer through a matching network and the input voltage of the transducer was monitored using a voltage probe (P6139A, Tektronix, Melrose, MA) connected to an oscilloscope (Handyscope HS5, Tiepie Engineering, Sneek, The Netherlands). The amplifier gain was set to deliver an output voltage Vout $=200 \mathrm{~V}$ peak-to-peak to the transducer.

A calibration was conducted before the UCA injection: at a given amplifier gain, the amplitude of the signal generated by the first function generator was ramped up to $0.6 \mathrm{~V}$ (with $0.02 \mathrm{~V}$ steps), corresponding to approximately $215 \mathrm{~V}$ after amplification. The generator amplitude corresponding to the closest amplified voltage below $200 \mathrm{~V}$ was chosen for the experiments. Different harmonics type responses were analyzed from the PCD recording.

The levels of the different harmonics types (harmonics $n * f_{0}$, subharmonic $f_{0} / 2$ and ultraharmonics $\left.(n+1 / 2) * f_{0}\right)$ and the broadband were recorded for this given voltage and used as baseline. 
bioRxiv preprint doi: https://doi.org/10.1101/351270; this version posted June 20, 2018. The copyright holder for this preprint (which was not certified by peer review) is the author/funder, who has granted bioRxiv a license to display the preprint in perpetuity. It is made available under aCC-BY 4.0 International license.

In order to estimate the peak pressure in the brain, a clean and degassed primate skull specimen (Maccaca Mulatta skull) was put in front of the transducer in a degassed water tank and the pressure at the focus was estimated using a heterodyne interferometer ${ }^{76}$. A heterodyne interferometer uses a laser beam to detect the vibration of a Mylar membrane induced by the ultrasound wave with. The amplitude of the vibration is then converted to pressure with high sensibility and a flat frequency response ${ }^{77}$.

The transmission of ultrasound through the degassed primate skull was assessed at 6 different points randomly chosen on the skull. The transmission was found to be $82 \% \pm 6 \%$. The in situ pressure delivered to the monkey brain transcranially was subsequently estimated at $0.54 \pm 0.03 \mathrm{MPa}$.

The equivalent Mechanical index (MI) value is 1.1 with an Intensity Spatial Peak Pulse Average (ISPPA) of $9.7 \mathrm{~W} / \mathrm{cm}^{2}$ in the brain. By taking into account the pulse duration and pulse repetition frequency (respectively $20 \mathrm{~ms}$ and $1 \mathrm{~Hz}$, corresponding to a $2 \%$ duty cycle) during the sequence, the Intensity Spatial Peak Time Average (ISPTA) is estimated to be $194 \mathrm{~mW} / \mathrm{cm}^{2}$ behind the primate skull.

\section{Visual stimuli and VEP recordings}

The animals were installed in a sphinx position in front of a black screen. Eyes were kept opened and gel (Ocry-gel, TVM, France) was applied to avoid eyes drying. A run of visual stimuli consisted in 200 full field flashes separated by 2 s intervals. Two electrodes were inserted symmetrically in the skin above the V1 regions. The reference electrode was subcutaneously inserted in the eye brows and the ground electrode in the maxilla. The VEPs were recorded on a MAP system (Plexon Inc., TX, USA).

Sham sessions were performed without any ultrasound sonication nor UCA and GABA injection, but the timing of VEP recordings was identical to a non-sham session. The transducer was positioned on the animal head in order to reproduce the non-sham conditions but was turned off.

\section{$M R I$}

We ran two experiments of BBB opening without the visual stimuli but with MRI assessment of Gadolinium (Gd) diffusion on monkey A. The MR contrast agent (MRCA) was gadoterate meglumine (Dotarem ${ }^{\circledR}$, Guerbet, France). We used a dose of $2 \mathrm{~mL}$ of a $0.5 \mathrm{mmol} / \mathrm{mL}$ Gd solution. The animal head was maintained with a stereotaxic frame during the image acquisition. Three MR acquisitions were obtained during the experiment. The first MRI acquisition was performed at baseline before sonication without MRCA. The second MRI acquisition was performed before sonication and 5 to 10 minutes after injection of the MRCA $(2 \mathrm{~mL})$, and the third acquisition was performed 15 minutes after sonication with a second MRCA injection 10 minutes after sonication. The second and third acquisitions were separated by a delay of about 25 minutes.

MRI was performed with a 3T magnet (Prisma, Siemens, Germany) using an 8-channel receive only head coil specifically designed for non-human primate experiments (Life Services LLC, USA). Images were acquired with a 2D-sagittal T1-weighted turbo spin-echo sequence with the following parameters: TR/TE: $689 / 11 \mathrm{~ms}$, Echo Train Length: 4; voxel size: $0.4 * 0.4 * 1.5 \mathrm{~mm}^{3}$, averages: 8,10 slices, acquisition time: 7 min $20 \mathrm{~s}$ ).

\section{Data analysis}

Electrophysiological data were post-processed using Matlab (MathWorks). The ground electrode signal was subtracted from the VEP recordings. The resulting signals were then filtered with a Savitzky-Golay filter (order 1, $21 \mathrm{~ms}$ frame length) and averaged (200 VEPs for a run). The offset, calculated as the mean of the first $50 \mathrm{~ms}$, was removed from each curve.

For the spectral power calculation, the signal was reduced to its period of interest (e.g. $0-100 \mathrm{~ms}$ after stimulus onset) before the Fourier transform. The spectral vector was then squared and summed over its length to get the spectral power. 
To standardize the analysis among the sessions, we always considered the five first GABA runs, even though we could acquire more data in some sessions. The exception is for Monkey A $-2 \mathrm{mg} / \mathrm{kg}$ and Monkey B $-1 \mathrm{mg} / \mathrm{kg}$ sessions, in which we have only 3 'GABA' runs.

In figure 5, the error bars represent the root mean square of the corresponding runs SEM (the ones giving minimum and maximum amplitudes).

In figure $\mathrm{S} 1$, the average harmonic response over 15 ultrasound pulses is represented on a logarithmic scale as the Fourier transform of the time signals before and after UCA injection. The plots are normalized by the resonant response at $\mathrm{f}_{0}$ after UCA injection.

\section{Supplementary material}

\begin{tabular}{|c|c|c|c|c|c|c|c|c|c|}
\hline \multirow{2}{*}{$\begin{array}{l}\text { Monkey \# } \\
\text { experiment } \\
\text { number }\end{array}$} & \multirow{2}{*}{$\begin{array}{c}\text { GABA } \\
\text { dose } \\
(\mathrm{mg} / \mathrm{kg})\end{array}$} & \multicolumn{7}{|c|}{ Maximum relative augmentation } & \multirow{2}{*}{$\begin{array}{c}\text { Time above } \\
\text { the } \\
\text { efficiency } \\
\text { threshold }\end{array}$} \\
\hline & & broadband & $\mathrm{n} * \mathrm{f}_{0}$ & $f_{0} / 2$ & $(\mathrm{n}+1 / 2) * \mathrm{f}_{0}$ & $\mathrm{f}_{0} / 3$ & $\mathrm{f}_{0} / 4$ & $f_{0} / 6$ & \\
\hline Monkey B & 1 & 1.2 & 0.6 & 2.3 & 1.2 & 5.3 & 1.9 & 2.0 & 21 \\
\hline Monkey B & 1 & 0.83 & 7.5 & 40 & 16 & 13 & 8.6 & 3.5 & 70 \\
\hline Monkey A & 2 & 0.57 & 6.0 & 25 & 16 & 12 & 7.9 & 2.1 & 140 \\
\hline Monkey A & 4 & 0.08 & 1.5 & 46 & 3.2 & 0.7 & 0.4 & 0.3 & 150 \\
\hline Monkey B & 4 & 1.2 & 4.5 & 4.0 & 5.7 & 5.7 & 3.5 & 2.5 & $>118$ \\
\hline Monkey A & 5 & 0.07 & 3.5 & 19 & 5.4 & 0.1 & 0.2 & 0.2 & 65 \\
\hline Monkey A & 6 & 0.23 & 3.5 & 5.3 & 14.6 & 4.9 & 6 & 1.3 & 56 \\
\hline Monkey A & 6 & 0.2 & 4.9 & 38 & 8.7 & 0.7 & 0.9 & 0.3 & 27 \\
\hline Monkey A & 6 & 0.8 & 12 & 59 & 23 & 16 & 11 & 6 & $>157$ \\
\hline Monkey B & 6 & 1.1 & 8.1 & 80 & 21.1 & 7.1 & 5.7 & 3.1 & $>135$ \\
\hline
\end{tabular}

Table 1: Maximum relative augmentation and time above the efficiency threshold for the subharmonic. 


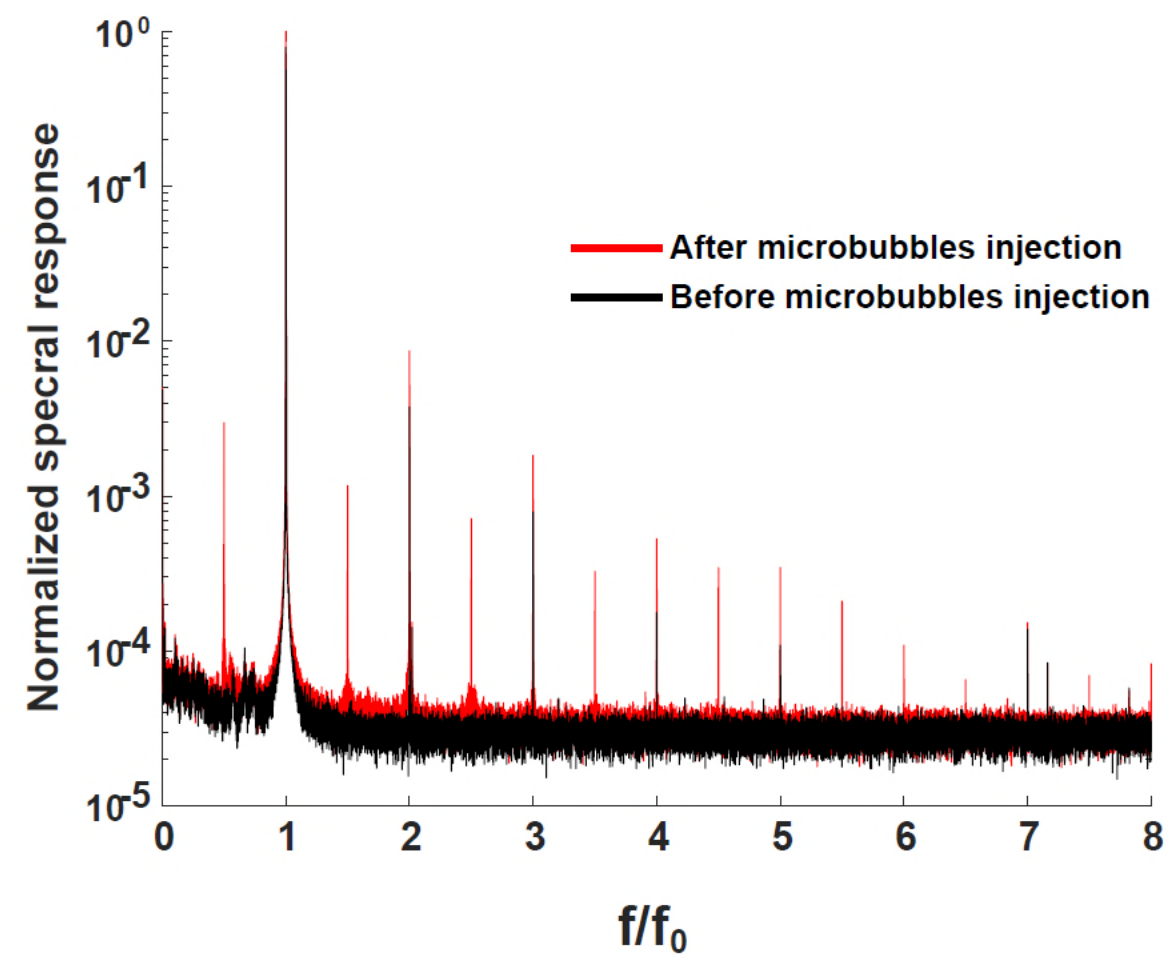

Figure S1: Spectral UCA response summed over $t=1$ to $t=15$ (before microbubbles injection) and over $t=45$ to $t=60$ (after microbubbles injection) on a logarithmic scale, session Monkey A $5 \mathrm{mg} / \mathrm{kg}$. The excitation frequency was $f_{0}=245 \mathrm{kHz}$.

\section{Acknowledgements}

We thank Sophie Rivaud-Péchoux for her help on the statistical analysis.

This work has been supported by the Bettencourt Schueller Foundation, the LABEX WIFI (Laboratory of Excellence within the French Program 'Investments for the Future') under references ANR-10LABX-24 and ANR-10-IDEX-0001-02 PSL, by the National Agency for Research under the program 'future investments' with the reference ANR-10-EQPX-15, IHU-A-ICM, Paris Institute of Translational neuroscience (IAIHU-06), France Life Imaging (ANR-11-INBS-0006), and NeurATRIS (ANR-11INBS-0011 translational research infrastructure for biotherapies in neuroscience).

\section{References}

1. Abbott, N. J. \& Romero, I. A. Transporting therapeutics across the blood-brain barrier. Mol. Med.

Today 2, 106-113 (1996).

2. Misra, A., Ganesh, S., Shahiwala, A. \& Shah, S. P. Drug delivery to the central nervous system: a review. J. Pharm. Pharm. Sci. Publ. Can. Soc. Pharm. Sci. Soc. Can. Sci. Pharm. 6, 252-273 (2003).

3. Aryal, M., Arvanitis, C. D., Alexander, P. M. \& McDannold, N. Ultrasound-mediated blood-brain barrier disruption for targeted drug delivery in the central nervous system. Adv. Drug Deliv. Rev.

72, 94-109 (2014). 
4. Kroll, R. A. \& Neuwelt, E. A. Outwitting the blood-brain barrier for therapeutic purposes: osmotic opening and other means. Neurosurgery 42, 1083-1099; discussion 1099-1100 (1998).

5. Pardridge, W. M. The Blood-Brain Barrier: Bottleneck in Brain Drug Development. NeuroRX 2, 314 (2005).

6. Hynynen, K., McDannold, N., Vykhodtseva, N. \& Jolesz, F. A. Noninvasive MR Imaging-guided Focal Opening of the Blood-Brain Barrier in Rabbits. Radiology 220, 640-646 (2001).

7. Hynynen, K., McDannold, N., Sheikov, N. A., Jolesz, F. A. \& Vykhodtseva, N. Local and reversible blood-brain barrier disruption by noninvasive focused ultrasound at frequencies suitable for trans-skull sonications. Neurolmage 24, 12-20 (2005).

8. Benjamin Marty et al. Dynamic Study of Blood-Brain Barrier Closure after its Disruption using Ultrasound: A Quantitative Analysis. J. Cereb. Blood Flow Metab. 32, 1948-1958 (2012).

9. Baseri, B., Choi, J. J., Tung, Y.-S. \& Konofagou, E. E. Multi-Modality Safety Assessment of BloodBrain Barrier Opening Using Focused Ultrasound and Definity Microbubbles: A Short-Term Study. Ultrasound Med. Biol. 36, 1445-1459 (2010).

10. Vykhodtseva, N. I., Hynynen, K. \& Damianou, C. Histologic effects of high intensity pulsed ultrasound exposure with subharmonic emission in rabbit brain in vivo. Ultrasound Med. Biol. 21, 969-979 (1995).

11. McDannold, N., Vykhodtseva, N., Jolesz, F. A. \& Hynynen, K. MRI investigation of the threshold for thermally induced blood-brain barrier disruption and brain tissue damage in the rabbit brain. Magn. Reson. Med. 51, 913-923 (2004).

12. Liu, H.-L. et al. Magnetic resonance monitoring of focused ultrasound/magnetic nanoparticle targeting delivery of therapeutic agents to the brain. Proc. Natl. Acad. Sci. 107, 15205-15210 (2010).

13. Fan, C.-H., Lin, C.-Y., Liu, H.-L. \& Yeh, C.-K. Ultrasound targeted CNS gene delivery for Parkinson's disease treatment. J. Controlled Release 261, 246-262 (2017). 
14. McDannold, N., Arvanitis, C. D., Vykhodtseva, N. \& Livingstone, M. S. Temporary Disruption of the Blood-Brain Barrier by Use of Ultrasound and Microbubbles: Safety and Efficacy Evaluation in Rhesus Macaques. Cancer Res. 72, 3652-3663 (2012).

15. Marquet, F., Tung, Y.-S., Teichert, T., Ferrera, V. P. \& Konofagou, E. E. Noninvasive, Transient and Selective Blood-Brain Barrier Opening in Non-Human Primates In Vivo. PLOS ONE 6, e22598 (2011).

16. McDannold, N., Vykhodtseva, N. \& Hynynen, K. Blood-Brain Barrier Disruption Induced by Focused Ultrasound and Circulating Preformed Microbubbles Appears to Be Characterized by the Mechanical Index. Ultrasound Med. Biol. 34, 834-840 (2008).

17. Carpentier, A. et al. Clinical trial of blood-brain barrier disruption by pulsed ultrasound. Sci. Transl. Med. 8, 343re2-343re2 (2016).

18. Bronstein JM, Tagliati M, Alterman RL \& et al. Deep brain stimulation for parkinson disease: An expert consensus and review of key issues. Arch. Neurol. 68, 165-165 (2011).

19. Mayberg, H. S. et al. Deep Brain Stimulation for Treatment-Resistant Depression. Neuron 45, 651-660 (2005).

20. Kringelbach, M. L., Jenkinson, N., Owen, S. L. F. \& Aziz, T. Z. Translational principles of deep brain stimulation. Nat. Rev. Neurosci. 8, 623-635 (2007).

21. Nitsche, M. A., Boggio, P. S., Fregni, F. \& Pascual-Leone, A. Treatment of depression with transcranial direct current stimulation (tDCS): A Review. Exp. Neurol. 219, 14-19 (2009).

22. Loo, C. K. \& Mitchell, P. B. A review of the efficacy of transcranial magnetic stimulation (TMS) treatment for depression, and current and future strategies to optimize efficacy. J. Affect. Disord. 88, 255-267 (2005).

23. Walsh, V. \& Cowey, A. Transcranial magnetic stimulation and cognitive neuroscience. Nat. Rev. Neurosci. 1, 73-80 (2000).

24. Wassermann, E. M. \& Lisanby, S. H. Therapeutic application of repetitive transcranial magnetic stimulation: a review. Clin. Neurophysiol. 112, 1367-1377 (2001). 
25. Chauvet, D. et al. Targeting accuracy of transcranial magnetic resonance-guided highintensity focused ultrasound brain therapy: a fresh cadaver model. J. Neurosurg. 118, 1046-1052 (2013).

26. Brunoni, A. R. et al. Clinical research with transcranial direct current stimulation (tDCS): Challenges and future directions. Brain Stimulat. 5, 175-195 (2012).

27. Mueller, J., Legon, W., Opitz, A., Sato, T. F. \& Tyler, W. J. Transcranial Focused Ultrasound Modulates Intrinsic and Evoked EEG Dynamics. Brain Stimul. Basic Transl. Clin. Res.

Neuromodulation 7, 900-908 (2014).

28. Lee, W. et al. Image-Guided Focused Ultrasound-Mediated Regional Brain Stimulation in Sheep. Ultrasound Med. Biol. 42, 459-470 (2016).

29. Tyler, W. J. et al. Remote Excitation of Neuronal Circuits Using Low-Intensity, Low-Frequency Ultrasound. PLOS ONE 3, e3511 (2008).

30. Tufail, Y. et al. Transcranial Pulsed Ultrasound Stimulates Intact Brain Circuits. Neuron 66, 681-694 (2010).

31. Legon, W. et al. Transcranial focused ultrasound modulates the activity of primary somatosensory cortex in humans. Nat. Neurosci. 17, 322-329 (2014).

32. Lee, W. et al. Image-Guided Transcranial Focused Ultrasound Stimulates Human Primary Somatosensory Cortex. Sci. Rep. 5, 8743 (2015).

33. Deffieux, T. et al. Low-Intensity Focused Ultrasound Modulates Monkey Visuomotor Behavior. Curr. Biol. 23, 2430-2433 (2013).

34. Wattiez, N. et al. Transcranial ultrasonic stimulation modulates single-neuron discharge in macaques performing an antisaccade task. Brain Stimulat. (2017). doi:10.1016/j.brs.2017.07.007

35. Younan, Y. et al. Influence of the pressure field distribution in transcranial ultrasonic neurostimulation. Med. Phys. 40, 082902 (2013).

36. King, R. L., Brown, J. R., Newsome, W. T. \& Pauly, K. B. Effective Parameters for UltrasoundInduced In Vivo Neurostimulation. Ultrasound Med. Biol. 39, 312-331 (2013). 
37. Ye, P. P., Brown, J. R. \& Pauly, K. B. Frequency Dependence of Ultrasound Neurostimulation in the Mouse Brain. Ultrasound Med. Biol. doi:10.1016/j.ultrasmedbio.2016.02.012

38. Li, G.-F. et al. Improved Anatomical Specificity of Non-invasive Neuro-stimulation by High Frequency (5 MHz) Ultrasound. Sci. Rep. 6, 24738 (2016).

39. Kamimura, H. A. S. et al. Focused ultrasound neuromodulation of cortical and subcortical brain structures using $1.9 \mathrm{MHz}$ : FUS neuromodulation of cortical/subcortical brain structures. Med. Phys. 43, 5730-5735 (2016).

40. Dallapiazza, R. F. et al. Noninvasive neuromodulation and thalamic mapping with lowintensity focused ultrasound. J. Neurosurg. 1-10 (2017). doi:10.3171/2016.11.JNS16976

41. Hu, Y., Zhong, W., Wan, J. M. F. \& Yu, A. C. H. Ultrasound can Modulate Neuronal Development: Impact on Neurite Growth and Cell Body Morphology. Ultrasound Med. Biol. 39, 915-925 (2013).

42. Scarcelli, T. et al. Stimulation of Hippocampal Neurogenesis by Transcranial Focused Ultrasound and Microbubbles in Adult Mice. Brain Stimulat. 7, 304-307 (2014).

43. Naor, O., Krupa, S. \& Shoham, S. Ultrasonic neuromodulation. J. Neural Eng. 13, 031003 (2016).

44. Sassaroli, E. \& Vykhodtseva, N. Acoustic neuromodulation from a basic science prospective. J. Ther. Ultrasound 4, 17 (2016).

45. van Gelder, N. M. \& Elliott, K. a. C. DISPOSITION OF Y-AMINOBUTYRIC ACID ADMINISTERED TO MAMMALS*. J. Neurochem. 3, 139-143 (1958).

46. McDannold, N. et al. Targeted, noninvasive blockade of cortical neuronal activity. Sci. Rep. 5, (2015).

47. Zhang, Y. et al. Non-Invasive, Focal Disconnection of Brain Circuitry Using Magnetic Resonance-Guided Low-Intensity Focused Ultrasound to Deliver a Neurotoxin. Ultrasound Med. Biol. 42, 2261-2269 (2016). 
48. Phelps, A. D. \& Leighton, T. G. The Subharmonic Oscillations And Combination-Frequency Subharmonic Emissions From A Resonant Bubble: Their Properties and Generation Mechanisms. Acta Acust. United Acust. 83, 59-66 (1997).

49. Neppiras, E. A. Acoustic cavitation. Phys. Rep. 61, 159-251 (1980).

50. Hwang, J. H., Tu, J., Brayman, A. A., Matula, T. J. \& Crum, L. A. Correlation between inertial cavitation dose and endothelial cell damage in vivo. Ultrasound Med. Biol. 32, 1611-1619 (2006).

51. Datta, S. et al. Correlation of cavitation with ultrasound enhancement of thrombolysis.

Ultrasound Med. Biol. 32, 1257-1267 (2006).

52. Ales, J. M., Yates, J. L. \& Norcia, A. M. V1 is not uniquely identified by polarity reversals of responses to upper and lower visual field stimuli. Neurolmage 52, 1401-1409 (2010).

53. Kelly, S. P., Schroeder, C. E. \& Lalor, E. C. What does polarity inversion of extrastriate activity tell us about striate contributions to the early VEP? A comment on Ales et al. (2010). Neurolmage 76, 442-445 (2013).

54. Schmolesky, M. T. et al. Signal timing across the macaque visual system. J. Neurophysiol. 79, 3272-3278 (1998).

55. Schroeder, C. E., Mehta, A. D. \& Givre, S. J. A spatiotemporal profile of visual system activation revealed by current source density analysis in the awake macaque. Cereb. Cortex N. Y. N 1991 8, 575-592 (1998).

56. Benevento, L. A. \& Yoshida, K. The afferent and efferent organization of the lateral geniculoprestriate pathways in the macaque monkey. J. Comp. Neurol. 203, 455-474 (1981).

57. Bullier, J. \& Kennedy, H. Projection of the lateral geniculate nucleus onto cortical area V2 in the macaque monkey. Exp. Brain Res. 53, 168-172 (1983).

58. Ptito, M., Johannsen, P., Faubert, J. \& Gjedde, A. Activation of human extrageniculostriate pathways after damage to area V1. Neurolmage 9, 97-107 (1999). 
59. Schmid, M. C., Panagiotaropoulos, T., Augath, M. A., Logothetis, N. K. \& Smirnakis, S. M. Visually driven activation in macaque areas V2 and V3 without input from the primary visual cortex. PloS One 4, e5527 (2009).

60. Sincich, L. C., Park, K. F., Wohlgemuth, M. J. \& Horton, J. C. Bypassing V1: a direct geniculate input to area MT. Nat. Neurosci. 7, 1123-1128 (2004).

61. Yoshida, K. \& Benevento, L. A. The projection from the dorsal lateral geniculate nucleus of the thalamus to extrastriate visual association cortex in the macaque monkey. Neurosci. Lett. 22, 103-108 (1981).

62. Sandell, J. H. \& Schiller, P. H. Effect of cooling area 18 on striate cortex cells in the squirrel monkey. J. Neurophysiol. 48, 38-48 (1982).

63. Hupé, J. M. et al. Cortical feedback improves discrimination between figure and background by V1, V2 and V3 neurons. Nature 394, 784-787 (1998).

64. Hupé, J. M., James, A. C., Girard, P. \& Bullier, J. Response modulations by static texture surround in area V1 of the macaque monkey do not depend on feedback connections from V2.J. Neurophysiol. 85, 146-163 (2001).

65. Sillito, A. M., Cudeiro, J. \& Jones, H. E. Always returning: feedback and sensory processing in visual cortex and thalamus. Trends Neurosci. 29, 307-316 (2006).

66. Hupé, J. M. et al. Feedback connections act on the early part of the responses in monkey visual cortex. J. Neurophysiol. 85, 134-145 (2001).

67. Juan, C.-H. \& Walsh, V. Feedback to V1: a reverse hierarchy in vision. Exp. Brain Res. 150, 259-263 (2003).

68. Silvanto, J., Lavie, N. \& Walsh, V. Double dissociation of V1 and V5/MT activity in visual awareness. Cereb. Cortex N. Y. N 1991 15, 1736-1741 (2005).

69. Yoo, S.-S. et al. Focused ultrasound modulates region-specific brain activity. Neurolmage 56, 1267-1275 (2011). 
70. Elias, W. J. et al. A Pilot Study of Focused Ultrasound Thalamotomy for Essential Tremor.

http://dx.doi.org/10.1056/NEJMoa1300962 (2013). Available at:

http://www.nejm.org/doi/full/10.1056/NEJMoa1300962. (Accessed: 24th May 2016)

71. Elias, W. J. et al. A magnetic resonance imaging, histological, and dose modeling comparison of focused ultrasound, radiofrequency, and Gamma Knife radiosurgery lesions in swine thalamus. J. Neurosurg. 119, 307-317 (2013).

72. Lipsman, N. et al. MR-guided focused ultrasound thalamotomy for essential tremor: a proofof-concept study. Lancet Neurol. 12, 462-468 (2013).

73. Marsac, L. et al. Ex vivo optimisation of a heterogeneous speed of sound model of the human skull for non-invasive transcranial focused ultrasound at $1 \mathrm{MHz}$. Int. J. Hyperthermia 33, 635-645 (2017).

74. Eames, M. D., Hananel, A., Snell, J. W., Kassell, N. F. \& Aubry, J.-F. Trans-cranial focused ultrasound without hair shaving: feasibility study in an ex vivo cadaver model. J. Ther. Ultrasound 1,24 (2014).

75. Maimbourg, G., Houdouin, A., Deffieux, T., Tanter, M. \& Aubry, J.-F. 3D-printed adaptive acoustic lens as a disruptive technology for transcranial ultrasound therapy using single-element transducers. Phys. Med. Biol. 63, 025026 (2018).

76. Constans, C., Deffieux, T., Pouget, P., Tanter, M. \& Aubry, J. F. A $200-1380$ kHz

Quadrifrequency Focused Ultrasound Transducer For Neurostimulation In Rodents And Primates: Transcranial In Vitro Calibration And Numerical Study Of The Influence Of Skull Cavity. IEEE Trans. Ultrason. Ferroelectr. Freq. Control PP, 1-1 (2017).

77. Royer, D. \& Casula, O. Quantitative imaging of transient acoustic fields by optical heterodyne interferometry. in , 1994 IEEE Ultrasonics Symposium, 1994. Proceedings 2, 1153-1162 vol.2 (1994). 